\title{
$O$ custo de conformidade à tributação no processo orçamentário em uma indústria alimentícia
}

\section{Taxation compliance costs in the budget process in a food processing business}

\author{
Marcus Vinicius Moreira Zittei ${ }^{1}$ \\ Antonio Maria da Silva Carpes ${ }^{2}$ \\ Carlos Eduardo Facin Lavarda ${ }^{3}$ \\ Glaucia Azevedo Martins ${ }^{4}$
}

\section{Resumo}

O Custo de Conformidade à Tributação corresponde aos dispêndios financeiros incorridos pelos contribuintes no cumprimento das determinações legais, contábeis e tributárias. Este artigo tem por objetivo averiguar a percepção dos gestores de uma empresa alimentícia limitada de grande porte quanto à participação dos Custos de Conformidade à Tributação (CCT) no processo orçamentário. A pesquisa classificase como de natureza qualitativa, com delineamento exploratório-descritivo. Quanto aos meios, trata-se de um estudo de caso único, em que foram utilizadas como fontes de evidências a pesquisa documental, questionário e roteiro de entrevista semiestruturada. A abordagem do problema é predominantemente qualitativa. Os resultados mostram que a empresa pesquisada conhece intuitivamente seus Custos de Conformidade à Tributação, porém, não os mensuram, favorecendo o surgimento de desvios no orçamento.

Palavras-chave: Custos de Conformidade à Tributação. Controladoria. Processo orçamentário.

\footnotetext{
1 Mestre em Ciências Contábeis, Doutorando em Ciências Contábeis e Administração pela Fundação Universidade Regional de Blumenau, Professor da Fundação Escola de Comércio Álvares Penteado, Rua Francisco Valente, 173, Apto. 91F, Jd. Esther Yolanda, São Paulo, SP, 05374-110, 11-30320431 - Brasil - marcuszittei@zittei.com.br

2 Mestre em Ciências Contábeis, Doutorando em Ciências Contábeis e Administração pela Fundação Universidade Regional de Blumenau, Professor da Universidade Federal da Fronteira Sul - Brasil - email: carpes.antonio@gmail.com

3 Doutor em contabilidade, Professor da Fundação Universidade Regional de Blumenau - Brasil clavarda@furb.br

4 Contadora, Estudante FECAP/FIPECAFI - Brasil - martins.glaucia@uol.com.br
} 


\section{Abstract}

Taxation Compliance Cost corresponds to all financial and non-financial outlays, incurred by taxpayers to comply with all legal, accounting and tributary requirements. This paper aims to ascertain the perception of the managers of a limited large food company, the participation of the Taxation Compliance Costs (TCC) in the budget process. The research is classified as qualitative, exploratory and descriptive in design. As for the means, this is a single case study, in which were used as sources of evidence in documentary research, questionnaire and semi-structured interview. Regarding the approach to the problem is predominantly qualitative. The results show that the company researched intuitively knows its Taxation Compliance Costs, but do not measure them, favoring the emergence of deviations in the budget.

Keywords: Compliance Costs of Taxation. Accountabilty. Budget process.

\section{Introdução}

A excessiva carga tributária tem se confirmado como um elevado custo para as sociedades. Segundo dados do Instituto Brasileiro de Planejamento Tributário e da Receita Federal do Brasil, o Brasil apresenta uma carga tributária em constante ascensão, alcançando recordes de arrecadação nas diversas esferas governamentais federal, estadual e municipal (IBPT, 2012).

Ao se mencionar carga tributária, é necessário considerar toda a cadeia de valor envolvida, observando-se outros gastos com controle e gerenciamento das atividades tributárias. Para Bertolucci (2002), podem ocorrer situações distintas, tendo em vista que qualquer país pode ter carga tributária muito alta e um sistema tributário racional, assim como pode ter carga tributária baixa e um sistema tributário caótico. No Brasil, há a combinação dos dois pontos: carga tributária muito alta e sistema tributário caótico.

A junção de uma elevada carga tributária dentro de um confuso sistema tributário acarreta um peso na estrutura orçamentária das empresas, haja vista que o referido valor pode ser vislumbrado diretamente no repasse ao preço de venda ou na diminuição dos resultados, pelo custo fixo que não pode ser repassado ao preço. 
Nessa linha de pensamento, insere-se a denominação de Custos de Conformidade à Tributação (CCT).

O estudo acerca dos CCT, mesmo em países mais desenvolvidos, iniciou em meados da década de 1980. No Brasil, parte dos referidos custos está mencionada no Código Tributário Nacional, em Obrigações Acessórias. Na Inglaterra, encontra-se um dos centros mais desenvolvidos em estudo dos CCT (BERTOLUCCI, 2001).

Evans (2003) revela que, até meados do século XX, muito pouco havia sido feito em pesquisas sobre os Custos de Conformidade à Tributação. No Brasil, embora a carga tributária seja um tema contemporâneo de discussão no meio acadêmico e empresarial, conforme Bertolucci (2001), houve interesse sobre a questão da conformidade à tributação. Porém, na conjuntura atual, tem-se percebido um crescente interesse acadêmico quanto a esse assunto, uma vez que este estudo utilizou-se de inúmeros trabalhos desenvolvidos por colegas, mestres e doutores em Contabilidade, Finanças e Tributos.

Sandford, Godwin e Hardwick (1989) categorizam os CCT em três tipos. Primeiramente, os impostos arrecadados pelo governo. Um segundo grupo é denominado como custos de distorção, os quais correspondem às variações econômicas ocasionadas pela influência dos impostos no preço das mercadorias. A terceira denominação diz respeito aos custos operacionais tributários, correspondentes aos recursos despendidos para operar o sistema tributário.

Identificar o conjunto de custos envolvidos na cadeia tributária, a partir da contemplação de que os custos monetários dos tributos são apenas uma parte, resulta em uma importante contribuição para a gestão dos resultados da empresa. Outrossim, o levantamento dos CCT traz, além de questões conceituais, problemas de ordem prática, considerando a intangibilidade inerente para se averiguar com exatidão os custos envolvidos (BERTOLUCCI, 2001).

As questões conceituais levantadas têm como pressuposto que o custo tributário brasileiro está associado à visão focada no valor dos 
impostos, unicamente. Soma-se o fato da complexidade do sistema tributário brasileiro, que dificulta uma visão mais abrangente das variáveis que compõem todo o sistema. Frente ao referido contexto, inserem-se as organizações, independentemente do seu porte, que têm de competir no acirrado mercado.

As organizações, atualmente, buscam adaptar-se ao ambiente altamente competitivo em que estão inseridas. Nesse sentido, voltamse não somente aos impactos externos, mas de forma necessária e relevante ao foco interno. É necessário estruturar um sistema que contemple um processo de planejamento e acompanhamento de sua execução, de modo a aperfeiçoar os recursos da organização (OTLEY, 1994). Reitera Alegria (1996) que o processo orçamentário apoia o planejamento estratégico, haja vista que o orçamento traz em sua estrutura um detalhamento devidamente mensurado das ações preestabelecidas no planejamento. Ao se considerar a participação dos CCT nos resultados da organização, administrá-los torna-se relevante para um bom delineamento do planejamento.

A partir dessas premissas, investiga-se, por meio de um estudo de caso, o referido tema. Isso posto, indaga-se: como se apresenta, na percepção dos gestores de uma empresa alimentícia limitada de grande porte, a participação dos Custos de Conformidade à Tributação (CCT) no processo orçamentário? Diante da questão-problema, define-se o que o presente artigo objetiva averiguar: a percepção dos gestores de uma empresa alimentícia limitada de grande porte quanto à participação dos CCT no processo orçamentário.

A referida proposta de pesquisa envolve os gestores de diversas áreas da organização estudada, no intuito de averiguar as possíveis diferenças conceituais, verificadas na análise da percepção dos gestores, assim como investigar de modo específico a participação no processo orçamentário. A presente pesquisa tem como base os estudos de Bertolucci (2001) e Bertolucci (2003), que levantam as primeiras questões sobre o tema. Nessa mesma linha, outro estudo diz respeito 
ao trabalho de Maia et al. (2008), que levanta a mesma questão em uma organização pública.

\section{Referencial teórico}

Nesta seção, são apresentados os conceitos relacionados aos Custos de Conformidade à Tributação e ao processo orçamentário, no intuito de fundamentar o debate dentro da problemática investigada.

\subsection{Custos de Conformidade à Tributação}

Os Custos de Conformidade à Tributação correspondem aos recursos necessários despendidos ao cumprimento das determinações legais tributárias pelos contribuintes. Também informações prestadas ao fisco em âmbito federal, estadual ou municipal, relativas a impostos e contribuições, inclusões e exclusões realizadas por determinação das normas tributárias, atendimento a fiscalizações, alterações da legislação, autuações e processos administrativos e judiciais, entre outros (BERTOLUCCI, 2001).

Sandford, Godwin e Hardwick (1989), precursores dos estudos relacionados ao CCT, ao categorizarem os custos inerentes ao processo tributário (tributos, distorção e operacionais), ressaltam que os custos de operacionalização incorporam a somatória dos custos administrativos (custos do poder público) e custos de conformidade (custos impostos ao contribuinte pelo cumprimento de suas obrigações).

Os custos administrativos representam os recursos do poder público destinado a legislar, arrecadar, controlar e julgar as questões relativas a tributos. Já os custos de conformidade abrangem as pessoas físicas e jurídicas que têm de cumprir as obrigações principais e acessórias definidas pelo poder público. Evans (2000) afirma que os custos de conformidade foram tratados por muito tempo como "custos ocultos" da tributação e que um consenso a respeito do significado preciso do termo compliance costs of taxation somente começou a emergir na literatura há aproximadamente 25 anos. 
Sandford, Godwin e Hardwick (1989) classificam os custos de conformidades à tributação em três tipos: (i) custos monetários diretos; (ii) custos temporários; e (iii) custos psicológicos. Os custos monetários correspondem à estrutura operacional para executar as atividades inerentes ao preenchimento de declarações e outros documentos que atendam as exigências do fisco. Quanto aos custos temporários, trata-se do tempo necessário para a execução das atividades que envolvem a operacionalização das atividades fiscais. Por fim, os custos psicológicos referem-se ao estresse que envolve a relação entre contribuinte e fisco (poder público).

Outras duas definições importantes, ainda no âmbito de CCT, são os custos monetários e os custos não monetários. Conforme Warburton e Hendy (2006), custos monetários são aqueles que estão incorporados ao desempenho financeiro dos negócios e, provavelmente, refletidos no lucro da empresa. Os custos de conformidade não monetários são custos intangíveis, cuja mensuração exata é de difícil tarefa, associados à operação do sistema tributário. Os referidos custos estão possivelmente refletidos nos resultados das empresas(EVANS; TRA-NAM, 2001).

Tratando-se ainda de conceitos, Sandford, Godwin e Hardwick (1989) distinguem os custos de conformidade nas categorias transitórias e recorrentes. Os autores trazem o termo "custos transitórios" como comumente usado para referir-se a custos de início (commencement or start-up cost) e custos temporários (temporary costs). Os custos recorrentes ou regulares (recurrent or regular costs) são aqueles que se mantêm mesmo depois da fase inicial do processo.

Bertolucci (2001), pioneiro no estudo dos CCT no Brasil, entende que a descentralização da legislação tributária representaria um elevado custo para os contribuintes. À medida que os constituintes determinassem que os impostos fossem de competência de vários entes, mas impondo uma legislação federal e homogênea, as empresas não sofreriam tanta oneração. $\mathrm{O}$ autor acrescenta a instabilidade das normas tributárias brasileiras e a complexidade gerada pela complexidade da legislação tributária no Brasil. 
Bertolucci inicia os estudos no Brasil sobre CCT (BERTOLUCCI, 2001; BERTOLUCCI; NASCIMENTO, 2002) apresentando um panorama em diversos países e uma pesquisa com empresas de capital aberto. Dos 13 países investigados, a Austrália apresenta o maior CCT em relação às receitas $(12,1 \%)$. Nas empresas brasileiras de capital aberto, mensurouse em $0,32 \%$ o custo sobre a receita, mas percebeu-se que quanto maior a empresa menor seu custo de conformidade à tributação. Na sua amostra, empresas com faturamento até $\mathrm{R} \$ 100$ milhões identificaram um custo de $1,66 \%$, e de $\mathrm{R} \$ 5$ a 15 bilhões mensuram em $0,14 \%$.

No estudo de Maia et al. (2008), são investigados os CCT em uma empresa estadual de saneamento básico, procurando verificar a percepção dos gestores. Os entrevistados entendem a importância e a existência dos referidos custos, mas não há esse debate e preocupação na organização, pois a atenção está na redução dos impostos efetivamente pagos através de técnicas de planejamento tributário.

Dessa forma, entende-se que os Custos de Conformidade à Tributação podem ser gerados em decorrência da instabilidade da legislação tributária, somada à complexidade do texto legal, que impõe às empresas dispêndios de recursos em inúmeras atividades, como pesquisas, revisão fiscal, planejamento tributário, contratação de consultorias, além das tarefas de conformidade fiscal.

\subsection{Processo orçamentário}

O orçamento consiste em uma ferramenta gerencial amplamente utilizada pelas organizações no processo de gestão, refletindo monetariamente nas ações para viabilizar o alcance dos objetivos estratégicos em determinado período. O processo orçamentário constituise um dos pilares da gestão e um mecanismo de operacionalização do accountability, o qual, por sua vez, é essencial ao gerenciamento do negócio (DAVILA; WOUTERS, 2005).

Entretanto, o orçamento é um produto de um plano estratégico preestabelecido pelos gestores. A estratégia consiste na montagem de 
um plano que assegure, com certo grau de confiabilidade, a efetividade das expectativas da organização, no que tange aos objetivos. As referidas metas consideram históricos passados, porém, há possibilidade de mudanças de rota ocasionadas pelas variações do ambiente, que levam à construção de estratégias alternativas (MINTZBERG; AHLSTRAND; LAMPEL, 2000; MINTZBERG; WATERS, 1982).

O orçamento, enquanto instrumento de apoio à gestão, também agrupa uma série de informações, não necessariamente convergentes, num artefato que serve para diferentes propósitos, como o planejamento e a organização das atividades, a alocação de recursos, a motivação de empregados, o planejamento do resultado, a avaliação do desempenho e a obtenção de conformidade com as normas socioeconômicas vigentes (COVALESKI et al., 2003; HANSEN et al., 2003).

O tema orçamento vem sendo tratado dentro do estudo da contabilidade gerencial, apresentado como instrumento de planejamento e controle útil no alcance das metas traçadas pela organização (COVALESKI et al., 2003; HANSEN et al., 2003). As metas asseguram o direcionamento das estratégias traçadas, que por sua vez são acompanhadas mediante controle eficaz. O referido processo de controle orçamentário contempla uma sequência lógica que se consolida na construção do orçamento empresarial (HERATH; INDRANI, 2007).

Embora possa parecer conceitualmente simples, a transformação das estratégias em um plano operacional, refletindo no orçamento, pode apresentar sérias dificuldades, visto que seus componentes variam de empresa para empresa, tanto no que diz respeito aos seus elementos quanto ao escopo das decisões, tomadas em diferentes graus de abrangência (FREZATTI et al., 2001). O orçamento consiste no plano financeiro para implementar as estratégias da organização, envolvendo proposições de planejamento, controle e organização de processos (COVALESKI, EVANS III; SHIELDS, 2003).

Van der Stede (2001) menciona que o orçamento é um subconjunto do sistema de controle organizacional. Implica dizer que não deve ser planejado, analisado e utilizado isoladamente. Uma vez inserido, o 
orçamento, no âmbito do planejamento, é importante entendê-lo no processo, ou seja, qual o papel que os gestores desejam dar e qual a extensão do processo. Corresponde a definir os papéis do planejamento estratégico e do orçamento dentro da visão de uma entidade em particular. Nesse sentido, quais as funções e o grau de importância a serem atribuídos ao orçamento são definições que não se limitam ao discurso proposto pelos gestores, mas sim àquele observado na prática, a partir dos recursos disponibilizados e das condições existentes para a execução efetiva do processo de orçamento, incluindo o controle orçamentário.

Assim, entende-se que é no planejamento estratégico que deverão ser exploradas todas as possibilidades (objetivos, estratégias, políticas e planos) para a constituição de um orçamento eficaz, e que é nessa fase, também, que todos os envolvidos deverão convergir para a identificação e enumeração de pontos positivos ou negativos a serem mensurados financeiramente, constituindo-se o processo orçamentário.

\section{Metodologia}

A pesquisa realizada classifica-se como estudo de natureza qualitativa, delineado como exploratório-descritivo. Marconi e Lakatos (2010) argumentam que os estudos exploratório-descritivos buscam descrever completamente determinado fenômeno por meio de análises empíricas e teóricas. O estudo se desenvolveu a partir de um estudo de caso, no intuito de descrever a percepção dos CCT dentro do processo orçamentário, denotando características que se assemelham ao conceito referenciado.

A empresa em que se realizou a pesquisa é uma indústria de grande porte, com 800 empregados e de capital brasileiro. Sua atividade principal é a liofilização de alimentos, presente na cadeia produtiva de alimentos como fornecedora de matéria-prima e produtos finais. As unidades fabris estão localizadas na Grande São Paulo. 
O estudo de caso é utilizado para compreensão de processos que ocorrem dentro de um contexto social, sendo possível a utilização de uma teoria prévia a ser verificada na investigação (YIN, 2001).

$\mathrm{Na}$ coleta de dados, a pesquisa se valeu de diferentes fontes de evidenciação, como a pesquisa documental com o orçamento anual e o planejamento orçamentário; a elaboração de um questionário, com perguntas abertas e fechadas; e entrevistas semiestruturadas. Os referidos questionários e o roteiro de entrevistas consideraram os modelos trazidos nos trabalhos de Bertolucci (2001), Bertolucci (2003) e Maia et al. (2008).

Quanto aos aspectos praticidade e simplicidade, visando o foco, a formatação de tal questionário seguiu criteriosa análise e estudo, buscando primeiramente a identificação do pesquisado no quadro institucional da empresa pesquisada, passando-se posteriormente à sua importância e percepção do processo de planejamento orçamentário e Custos de Conformidade à Tributação.

Os questionários foram aplicados com 20 colaboradores em níveis de gestão, subordinados diretamente à Controladoria. Para um aprofundamento dos resultados, foram realizadas três entrevistas: uma com o controller, outra com o gerente de planejamento financeiro e uma terceira com a coordenadora fiscal. A coleta de dados se deu entre os dias 19 de dezembro de 2012 e 15 de janeiro de 2013. Fez-se necessário o acompanhamento e controle direto, tanto quanto a compreensão do questionamento, entendendo-se que agindo dessa forma se poderiam evitar distorções. Os dados coletados foram analisados de forma qualitativa, promovendo-se uma análise do conteúdo das respostas.

\section{Análise dos resultados}

A seguir, apresenta-se a análise dos questionários e entrevistas realizados em campo na empresa objeto de estudo. 


\subsection{Análise dos questionários}

Inicialmente, analisando-se o perfil dos entrevistados, verificaramse as funções desempenhadas: sete coordenadores, seis supervisores, quatro gerentes e três consultores internos. Quanto à formação, 10 tinham formação em Ciências Contábeis e oito fazem ou fizeram especialização. Quanto ao tempo de trabalho na organização, 10 dos entrevistados estavam há mais de cinco anos e menos de dez anos, sendo 8 na mesma função há mais de um ano. Percebeu-se que os participantes tinham conhecimentos sobre questões tributárias e sobre a realidade da empresa.

A seguir, os colaboradores responsáveis pelo apoio ao processo orçamentário responderam às questões pertinentes ao planejamento orçamentário. Os respondentes utilizaram-se de informações contábeis para tomada de decisões no processo orçamentário.

Quadro 1 - Participação na elaboração do planejamento orçamentário

\begin{tabular}{|l|l|}
\hline \multicolumn{2}{|l|}{ Participação na elaboração do planejamento orçamentário } \\
\hline $20,69 \%$ & Fornecem informações complexas a seus clientes internos. \\
\hline $18,97 \%$ & Auxiliam outros departamentos na elaboração de suas metas e objetivos. \\
\hline $15,52 \%$ & Analisam informações e confirmam a veracidade das mesmas. \\
\hline $13,79 \%$ & Fornecem informações básicas a seus clientes internos. \\
\hline $12,07 \%$ & $\begin{array}{l}\text { Controlam os resultados apresentados em quaisquer momentos do } \\
\text { planejamento orçamentário. }\end{array}$ \\
\hline $8,82 \%$ & $\begin{array}{l}\text { Parametrizam metas e objetivos em quaisquer momentos do planto } \\
\text { orçamentário. }\end{array}$ \\
\hline $8,62 \%$ & Fornecem dados estatísticos macroeconômicos à Presidência. \\
\hline $1,72 \%$ & Realizam outras atividades não enumeradas acima. \\
\hline
\end{tabular}

Fonte: Dados da pesquisa.

O Quadro 1 apresenta a participação na elaboração orçamentária, em que a atividade preponderante, na visão dos respondentes, é fornecer informações $(20,69 \%)$ aos diversos setores internos. Percebe-se, diante dos resultados, que a ação de apoio ao processo de planejamento e orçamento está sendo privilegiada diante das atividades de controle $(12,07 \%)$ e do apoio operacional ao planejamento $(8,82 \%)$. 
O Quadro 2 evidencia a percepção dos entrevistados quanto à influência dos CCT no planejamento orçamentário. As questões foram submetidas à escala Likert de sete pontos. Os resultados foram agrupados no intuito de contribuir na contextualização das respostas.

As duas primeiras questões (Quadro 2) relacionam a percepção do respondente frente ao planejamento estratégico e suas variáveis ambientais, demonstrando haver conhecimento da necessidade do planejamento estratégico como instrumento de apoio dentro da trajetória da organização. Entretanto, as respostas ficaram em um grau relativamente mediano, se considerada uma escala de sete pontos, o que pode sugerir diferentes conclusões. Por exemplo, é ponto pacífico que os respondentes compreendem o papel do planejamento estratégico; outrossim, uma resposta mais enfática pode estar associada ao distanciamento dos agentes respondentes no contexto do planejamento.

\section{Quadro 2 - Custos de Conformidade à Tributação x Planejamento Orçamentário}

\begin{tabular}{|l|l|}
\hline \multicolumn{2}{|l|}{ Custos de Conformidade à Tributação x Planejamento Orçamentário } \\
\hline $45 \%$ & $\begin{array}{l}\text { O planejamento orçamentário da empresa deve obrigar os gestores a pensarem no } \\
\text { futuro da empresa, tanto em demanda, quanto em oportunidades. }\end{array}$ \\
\hline $50 \%$ & $\begin{array}{l}\text { A empresa deve buscar estar alinhada a todas as demandas de seus clientes } \\
\text { externos, como preço, produto e conhecimento. }\end{array}$ \\
\hline $45 \%$ & $\begin{array}{l}\text { Dos entrevistados concordam ou concordam totalmente que no planejamento } \\
\text { orçamentário da empresa devem ser mensuradas todas as necessidades de } \\
\text { treinamento interno ou externo, assim como o tempo dispensado à pesquisas e } \\
\text { desenvolvimento da equipe para adequação à tributação vigente. }\end{array}$ \\
\hline $45 \%$ & $\begin{array}{l}\text { Dos entrevistados concordam totalmente que no planejamento orçamentário da } \\
\text { empresa devem ser mensuradas todas as necessidades de tempo e pessoas para } \\
\text { adequação à tributação vigente e as mudanças tributárias futuras. }\end{array}$ \\
\hline $43 \%$ & $\begin{array}{l}\text { Dos entrevistados concordam que no planejamento estratégico da empresa devem } \\
\text { ser mensurados os dispêndios psicológicos da equipe interna, como estresse, } \\
\text { ansiedade, atestados por afastamento, pedidos de demissão, contratações } \\
\text { emergenciais, entre outros. }\end{array}$ \\
\hline $35 \%$ & $\begin{array}{l}\text { Dos entrevistados concordam ou concordam totalmente que no planejamento } \\
\text { estratégico da empresa devem ser provisionados os possíveis dispêndios com } \\
\text { passivo trabalhista ou ambientais. }\end{array}$ \\
\hline $58 \%$ & $\begin{array}{l}\text { Dos entrevistados concordam totalmente que se seu departamento estimasse } \\
\text { tais dispêndios corretamente poderiam evitar distorções na realização de seus } \\
\text { orçamentos. }\end{array}$ \\
\hline
\end{tabular}

Fonte: Dados da pesquisa. 
As questões seguintes (Quadro 2) são mais focadas nos aspectos operacionais, relacionados aos CCT. Os respondentes apontaram ter conhecimento sobre a necessidade de se mensurar os custos de pessoal e seus reflexos legais em âmbito judiciário. Da mesma forma, nas conclusões dos respondentes, não foi dada ênfase ao custo de conformidade tributária (45\%), talvez pela dificuldade de mensuração ou desconhecimento da existência de um processo que promova identificação, mensuração e avaliação dos referidos custos.

Acrescenta-se à análise dos dados a assertiva sobre a relevância das provisões de passivos trabalhistas ou ambientais (35\%). O resultado sugere que a provisão, talvez por sua característica de previsão, seja algo mais difícil de se visualizar de modo efetivo.

\subsection{Identificação e mensuração dos CCT}

Após uma primeira leitura sobre a visão dos respondentes quanto à relação dos CCT no processo orçamentário, a análise segue a partir de questões mais voltadas ao escopo da identificação e mensuração dos CCT.

A maioria dos respondentes (55\%) conseguiu mensurar os CCT dentro de um montante que vai até $R \$ 100.000,00$. Entretanto, a partir desse montante, e considerando a amostra, 45\% dos respondentes não conseguem identificar ou mensurar os valores despendidos para com os CCT. Nesses dispêndios, estão associados gastos que estejam atrelados à complexidade da legislação tributária. Diante dessa primeira constatação, verificou-se qual a participação dos dispêndios no orçamento da empresa, cujos resultados são evidenciados na Tabela 1. 
Tabela 1 - Ações da empresa para tratamento dos CCT

\begin{tabular}{l|c|c|c|c|c}
\hline $\begin{array}{l}\text { Ações / } \\
\text { Aspectos }\end{array}$ & $\begin{array}{c}\text { Complexidade } \\
\text { da legislação } \\
\text { tributária \% }\end{array}$ & $\begin{array}{c}\text { Atendimento } \\
\text { fiscalizações/ } \\
\text { processos \% }\end{array}$ & $\begin{array}{c}\text { Impostos e } \\
\text { declarações } \\
\text { acessórias \% }\end{array}$ & $\begin{array}{c}\text { Alterações } \\
\text { normas } \\
\text { contábeis \% }\end{array}$ & $\begin{array}{c}\text { Planejamento } \\
\text { fiscal \% }\end{array}$ \\
\hline $\begin{array}{l}\text { Horas } \\
\text { trabalhadas pelos } \\
\text { colaboradores }\end{array}$ & 41 & 42 & 37 & 35 & 38 \\
\hline $\begin{array}{l}\text { Contratação, } \\
\text { assessorias } \\
\text { consultorias } \\
\text { terceirizadas }\end{array}$ & 35 & 38 & 37 & 31 & 40 \\
\hline $\begin{array}{l}\text { Treinamentos } \\
\text { (internos e } \\
\text { externos) }\end{array}$ & 14 & 08 & 15 & 19 & 11 \\
\hline $\begin{array}{l}\text { Estudos e } \\
\text { pesquisas da } \\
\text { legislação }\end{array}$ & 10 & 12 & 11 & 15 & 11 \\
\hline Total & 100 & 100 & 100 & 100 & 100 \\
\hline
\end{tabular}

Fonte: Dados da pesquisa.

Os aspectos selecionados consideraram os achados de Maia et al. (2008), sendo a tabela adaptada para a proposta de trabalho. As ações são as execuções operacionais dispostas na primeira coluna da Tabela 1, ao passo que os aspectos são os itens constantes da primeira linha horizontal da tabela. No presente estudo de caso, as ações relacionadas às horas de trabalho executadas, assim como as consultorias contratadas, despontaram como aquelas possíveis de se estimar dentro do orçamento.

Um fato que merece atenção é a não possibilidade ou falta de previsão factível das ações relacionadas a treinamento e pesquisa, diante dos aspectos considerados. Diante de uma legislação tributária complexa, com margem para interpretação, presume-se a necessidade de um estudo para que a empresa se posicione.

\subsection{Mensuração do CCT}

Diante do objetivo desta pesquisa, que é identificar os Custos de Conformidade à Tributação, verificou-se junto aos entrevistados (controller, gerente de planejamento financeiro e coordenadora 
fiscal) a possibilidade de se mensurar o referido custo. Elencaram-se os dispêndios relacionados aos referidos custos e tabularam-se os percentuais previsíveis na concepção dos entrevistados.

Diante da inquisição com os entrevistados, os dados evidenciam uma lacuna no processo de previsão de CCT, demonstrada pela média superior a $50 \%$ de respondentes que avaliaram ser impossível a mensuração. As maiores dificuldades de mensuração dizem respeito aos dispêndios voltados ao atendimento de fiscalização de processos, plano fiscal e alterações das normas contábeis.

Analisando-se o conjunto de informações, por meio de avaliação das médias de observações, os CCT estariam sendo avaliados, em média, com valores de até $\mathrm{R} \$ 100.000,00$. Comparando-se a estimativa de o CCT ser equivalente a $\mathrm{R} \$ 100.000,00$, o referido valor corresponderia a $0,83 \%$ do faturamento bruto orçado em 2012 (Ver Tabela 2).

Tabela 2 - Mensuração CCT

\begin{tabular}{l|c|c|c|c|c|c}
\hline $\begin{array}{l}\text { Participação / } \\
\text { Valores }\end{array}$ & $\begin{array}{c}\text { Complexidade } \\
\text { da legislação } \\
\text { tributária \% }\end{array}$ & $\begin{array}{c}\text { Atendimento } \\
\text { fiscalizações/ } / \\
\text { processos \% }\end{array}$ & $\begin{array}{c}\text { Impostos e } \\
\text { declarações } \\
\text { acessórias \% }\end{array}$ & $\begin{array}{c}\text { Alterações } \\
\text { normas } \\
\text { contábeis \% }\end{array}$ & $\begin{array}{c}\text { Plano } \\
\text { fiscal \% }\end{array}$ & Média \\
\hline Até $\mathrm{R} \$ 10.000,00$ & 10 & 0 & 10 & 20 & 0 & 8 \\
\hline Até $\mathrm{R} \$ 20.000,00$ & 10 & 10 & 0 & 0 & 0 & 4 \\
\hline Até $\mathrm{R} \$ 50.000,00$ & 10 & 0 & 5 & 5 & 15 & 7 \\
\hline Até $\mathrm{R} \$ 100.000,00$ & 15 & 25 & 40 & 15 & 15 & 22 \\
\hline $\begin{array}{l}\text { Acima de } \mathrm{R} \$ \\
100.000,00\end{array}$ & 10 & 15 & 0 & 5 & 10 & 8 \\
\hline $\begin{array}{l}\text { Não foi possível } \\
\text { mensurar }\end{array}$ & 45 & 60 & 45 & 55 & 60 & 53 \\
\hline
\end{tabular}

Fonte: Dados da pesquisa.

Tomando como parâmetro o estudo de Bertolucci (2001), em cuja pesquisa a amostra foi de 25 empresas, a representatividade do CCT era de $0,32 \%$ do faturamento. Percebendo que o percentual diminuía conforme aumentava a receita, o autor criou grupos por faturamento: de até R\$100.000.000,00, o CCT representa 1,66\%. Comparando-se isoladamente a referida informação, percebe-se um CCT inferior na 
empresa estudada, o que implicaria reflexo no orçamento da empresa, cuja estimativa foi de uma receita bruta de $\mathrm{R} \$ 12.000 .000,00$. Diante do objetivo desta pesquisa, que é identificar os Custos de Conformidade à Tributação, verificou-se junto aos entrevistados (controller, gerente de planejamento financeiro e coordenadora fiscal) a possibilidade de se mensurar o referido custo.

\section{Conclusão}

Este estudo teve por objetivo averiguar a percepção dos gestores de uma empresa alimentícia quanto à participação dos Custos de Conformidade à Tributação (CCT) no processo orçamentário.

A pesquisa foi realizada em uma indústria do segmento de liofilização de alimentos, presente na cadeia produtiva de alimentos como fornecedora de matéria-prima e produtos finais. As unidades fabris estão localizadas na Grande São Paulo. A pesquisa envolveu uma amostra composta de 23 pessoas, que responderam questões pertinentes à problemática que envolveu o estudo.

Diante da indagação que norteou a pesquisa, examinou-se o processo orçamentário na tentativa de averiguar a participação dos colaboradores. As respostas sugerem uma posição voltada para apoio ao processo de planejamento e análise do orçamento, prevalecendo diante de uma visão operacional do orçamento. Outrossim, a referida constatação não exclui nem desmerece o processo de execução orçamentária.

No que concerne à proposta de investigar a identificação e mensuração dos Custos de Conformidade à Tributação (CCT), os resultados demonstraram certa limitação dos respondentes quanto à percepção destes diante da possibilidade de identificar e mensurar os referidos custos. Com relação ao processo de identificação de dispêndios mais percebidos pelos respondentes estão as horas trabalhadas e os serviços de consultoria contratada. O olhar é inverso ao se observar os gastos com capacitação de pessoas. 
Quanto à mensuração dos CCT, constatou-se que estes se encaixam dentro de uma escala entre $R \$ 10.000,00$ (dez mil reais) e $R \$$ $100.000,00$ (cem mil reais). Utilizando-se do uso de médias, foi possível sugerir que o CCT analisado conjuntamente estaria em torno de R\$ 100.000,00.

Dentre os resultados, conclui-se que a empresa possui uma percepção intuitiva da existência dos Custos de Conformidade à Tributação, pois não há informações precisas sobre os itens que compõem esses custos, nem de mecanismos e dispositivos para apurá-los ou controlá-los. Mesmo assim, foi possível estimar um montante equivalente a $\mathrm{R} \$ 100.000,00$ (cem mil reais) de CCT, representando $0,83 \%$ da receita bruta prevista no orçamento de 2012 (R\$12.000.000,00).

Dessa forma, os resultados demonstram que ocultar ou não se considerar os CCT tratados e referenciados nesse estudo pode subavaliar a proposição de custos e, consequentemente, impactar no desempenho econômico da organização. Sugere-se, como pesquisa futura, uma pesquisa-ação (ou participante) para a construção de um modelo de mensuração do CCT, podendo-se identificá-los e quantificálos.

\section{Referências}

\section{ALEGRÍA, A. I. Z.. La función de control a traves de los}

presupuestos: aplicación a la empresa multinacional. Madrid: ICAC, 1996.

BERTOLUCCI, A. V. Uma contribuição ao Estudo da incidência dos Custos de Conformidade às Leis e Disposições Tributárias: um panorama mundial e pesquisa dos custos das companhias de Capital Aberto no Brasil. 2001, 178 f. Dissertação (Mestrado em Controladoria e Contabilidade) - Departamento de Contabilidade e Atuária, Faculdade de Economia, Administração e Contabilidade. Universidade de São Paulo - USP, São Paulo, 2001. 
.; NASCIMENTO, D. T. Quanto custa pagar tributos? Revista Contabilidade \& Finanças. Universidade de São Paulo - USP, São Paulo, v. 13 n. 29, p. 55-67, mai./ago. 2002.

CIANFANELLI, M.M.; PESSÔA, L.C.; MURITIBA, P. M. Custo de Conformidade à Tributação e o gerenciamento do risco em projetos: o estudo de caso de uma pequena empresa. Revista de Gestão e Projetos - GeP, [S.I.], v. 1, n. 1, p. 93-113, jan/jun. 2010.

CONCEIÇÃO, O. A. C. Instituições, crescimento e mudanças na ótica institucional. 2002, 228 f. Tese (Doutorado em História do Pensamento Econômico e Metodologia) - Fundação de Economia e Estatística, Siegfried Emanuel Heuser, Porto Alegre, 2002.

COVALESKI, M. A. et al. Budgeting research: three theoretical perspectives and criteria for selective integration. Journal of Management Accouting Research, [S.I.], v. 15, n. 1, p. 3-49, jul./set. 2003.

DAFT, R. L. Teoria e projeto das organizações. 6. ed. Rio de Janeiro: LTC, 1999.

DAS-GUPTA, A. The Income Tax Compliance Cost of Corporations in India. Vikalpa, [S.I.], v. 31, n. 4, p. 09-22, oct./dec., 2006. Disponível em: <http://www.vikalpa.com/pdf/articles/2006/2006_oct_dec_ page_9_30.pdf>. Acesso em: 30 nov. 2012.

DAVILA, A.; WOUTERS, M. Managing budget emphasis through the explicit design of conditional budgetary slack. Accouting Organizations and Society, [S.I.], v. 30, n. 7-8, p. 587-608, out/nov. 2005.

EVANS, C. Tax Compliance costs: research methodology and empirical evidence from Australia. National Tax Journal, [S.I.], v. 53, n. 2, p. 229-252, june, 2000. Disponível em: <http://papers.ssrn.com/sol3/ papers.cfm?abstract_id=228895>. Acesso em: 10 out. 2012.

. Studying the studies: an overniew of recent research into 
taxation operating costs. eJournal of Tax Research, Australia, v. 1, n. 1, p. 64-92, Semestral jan-jun. 2003. Disponível em: <https:// www.business.unsw.edu.au/research-site/publications-site/ ejournaloftaxresearch-site/Documents/full_edition_v1n1.pdf\#page=64>. Acesso em: 10 out. 2012.

. TRAN-NAM, B. The compliance and administrative cost of the TVM: wthat ate the implications? In: AUSTRALIAN TAX RESEARCH FOUDATION. ATAX AND THE BOARD OF TAXATION TAX VALUE METHOD CONSULTATIVE CONFERENCE. Austália: USNW, 2001. Disponível em <http://www.taxinstitute.com.au/publications/australiantax-research-foundation-atrf-materials/pageruleCustomObjects/4>. Acesso em 10 out. 2012.

FREITAS, C. A. S. Aprendizagem, isomorfismo e institucionalização: $O$ caso da atividade de auditoria operacional no Tribunal de Contas da União. 2005, 235f. Dissertação (Mestrado em Administração) - Programa de Pós-Graduação em Administração da Universidade de Brasília, Brasília, 2005.

FREZATTI, F. et al. Processo Orçamentário: uma aplicação da análise substantiva com utilização da Grounded Theory, O\&S, Salvador, v. 18, n. 58, p. 445-466, jul./set. 2011.

\section{Orçamento empresarial: planejamento e controle} gerencial. São Paulo: Atlas, 2009.

GUERREIRO, R. et al. O entendimento da Contabilidade Gerencial sob a ótica da Teoria Institucional. O\&S, Salvador, v. 12, n. 35, out./ dez. 2005.

.; FREZATTI, F.; CASADO, T. Em Busca de um Melhor

Entendimento da Contabilidade Gerencial através da Integração de Conceitos da Psicologia, Cultura Organizacional e Teoria Institucional. Revista Contabilidade \& Finanças, Universidade de São Paulo USP, São Paulo, Edição Comemorativa, p. 7-21, set. 2006. 
HANSEN, S. C.; OTLEY, D. T.; VAN DER STEDE, W. A. Pratice development in budgeting: an overview and research perspective. Journal oh Management Acoounting Research, [S.I.], v. 15, n. 1, p. 95-116, Dec. 2003.

HERATH, S. K.; INDRANI, M.W. Budgeting as a competitive advantage: evidence from Sri Lanka. Journal of America Academy of Business, Cambridge. v. 11, n. 1, p. 79-91, mar. 2007.

MACHADO-DA-SILVA, C. L.; GONÇALVES, S. A. Nota técnica: a teoria institucional. In: CLEGG, S.; HARDY, C.; NORD, W. R. (Orgs.). Handbook de estudos organizacionais. São Paulo: Atlas, 1998. p. 220226.

MAIA, G. L. et al. Custos de Conformidade à Tributação: uma análise da percepção de gestores e colaboradores em uma empresa estadual de saneamento. ABCustos Associação Brasileira de Custos, São Leopoldo(RS), v. 3, n. 3, p.45-67, set./dez. 2008.

MESQUITA, R. C. P. et al. Teoria Institucional e Controladoria: Estudo em Anais de Congresso nas Áreas Temáticas de Controladoria e Contabilidade Gerencial. In: SEMINÁRIO EM ADMINISTRAÇÃO SemeAd, 15., 2011, São Paulo. Anais... São Paulo: USP, 2011. p. $1-14$.

OTLEY, D. T. Management control in contemporary organizations: towards a wider framework. Management Accounting Research, [S.I.], v. 5, n.3-4, p. 289-299, sept. 1994.

OYADOMARI, J.C. et al. Fatores que Influenciam a Adoção de Artefatos de Controle Gerencial nas Empresas Brasileiras. Um estudo Exploratório Sob a Ótica da Teoria Institucional. Revista de Contabilidade e Organizações - FEARP/USP, Ribeirão Preto, v. 2, n. 2, p. 55-70, jan/abr. 2008.

REIS, L. G. A influência do discurso no processo de mudança da contabilidade gerencial: um estudo de caso sob o enfoque da 
teoria institucional. 2008, 187 p. Tese (Doutorado em Contabilidade e Gestão) - Faculdade de Economia, Administração e Contabilidade Universidade de São Paulo - USP, São Paulo, 2008.

REZENDE, C. Pandemônio Tributário. Disponível em: <http://www. iabnacional.org.br/IMG/pdf/doc-6068.pdf>. Acesso em: 01 dez. 2012.

SANDFORD, C.; GODWIN, M.; HARDWICK, P. Administrative and Complince Costs of Taxations. Bath, UK: Fiscal Publications, 1989.

TOLBERT, P. S., ZUCKER, L. G.. A Institucionalização da Teoria Institucional. Handbook de Estudos Organizacionais. v. 1. São Paulo: Atlas, 2007.

VAN DER STEDE, W.A. Measuring tight budgetary control.

Management Accounting Research, [S.I.], v. 12, n. 1, p.119-137, mar. 2001.

VENTURA, E. C. F. Dinâmica de institucionalização de práticas sociais: estudo de responsabilidade docial no campo das organizações bancárias. 2005, 351 p. Tese (Doutorado em Administração) - Centro de Formação Acadêmica e Pesquisa da Fundação Getúlio Vargas - FGV, São Paulo, 2005.

WARBURTON, R.; HENRY, P. International comparasation of Australia's Taxes.2006 Disponível em: <http://comparativetaxation. treasury.gov.au/content/default.asp>. Acesso em: 03 dez. 2012.

WEICK, K.. Aprendizagem organizacional: confirmando um oxímoro. In: CLEGG, Stewart R. et al.Handbook de estudos organizacionais: ação e análise organizacionais. São Paulo: Atlas, 2004. Cap. 16, p. 361-388.

Artigo recebido em: 22/04/2015

Aprovado em: 30/09/2015 